\title{
Finite Element Analysis of High-Speed Motorized Spindle Based on ANSYS
}

\author{
Deping Liu*, Hang Zhang, Zheng Tao and Yufeng Su
}

School of Mechanical Engineering, Zhengzhou University, Zhengzhou 450001, China

\begin{abstract}
This paper presents a method to investigate the characteristics of a high-speed motorized spindle system. The geometric quality of high-precision parts is highly dependent on the dynamic performance of the entire machining system, which is determined by the interrelated dynamics of machine tool mechanical structure and cutting process. This performance is of great importance in advanced, high-precision manufacturing processes. The state-of-the-art in machine tool main spindle units is focus on motorized spindle units for high-speed and high performance cutting. This paper taking the high-speed milling motorized spindle of CX8075 produced by Anyang Xinsheng Machine Tool Co. Ltd. as an example, a finite element model of the high-speed motorized spindle is derived and presented. The model takes into account bearing support contact interface, which is established by spring-damper element COMBIN 14. Furthermore, the static analysis, modal analysis, harmonic response analysis and thermal analysis were done by means of ANSYS commercial software. The results show that the maximum rotating speed of the motorized spindle is far smaller than the natural resonance region speed, and the static stiffness of the spindle can meet the requirements of design. The static and dynamic characteristics of the motorized spindle accord with the requirements of high-speed machining. The thermal deformation of spindle is $6.56 \mu \mathrm{m}$, it is too small to affect the precision of the spindle. The results illustrate the rationality of the spindle structural design.
\end{abstract}

Keywords: Motorized spindle, finite element analysis, ANSYS.

\section{INTRODUCTION}

In today's prosperous industrial development, with the multifarious design of products and reduction of production cycle, high speed machining technology has been widely adopted by manufacturers [1]. With the development of the science and technology, the high frequency spindles has been taken place of the normal mechanical spindles more and more, and also be used of the numerical control machine with great effects.

Classically, main spindles were driven by belts or gears and the rotational speeds could only be varied by changing either the transmission ratio or the number of driven poles by electrical switches. Later simple electrical or hydraulic controllers were developed and the rotational speed of the spindle could be changed by means of infinitely adjustable rotating transformers.

The need for increased productivity led to higher speed machining requirements which led to the development of new bearings, power electronics and inverter systems. The progress in the field of the power electronics led to the development of compact drives with low-cost maintenance using high frequency three-phase asynchronous motors. Through the early 1980's high spindle speeds were achievable only by using active magnetic bearings. Continuous developments in bearings, lubrication, the rolling element materials and drive systems have allowed the construction of

*Address correspondence to this author at the School of Mechanical Engineering, Zhengzhou University, Zhengzhou 450001, China; Tel: +8613598002376 (Mobile); Fax: +86-0371-67781786;

E-mails: liudeping66@163.com,ldp@zzu.edu.cn direct drive motor spindles which currently fulfill a wide range of requirements.

Today, the overwhelming majority of machine tools are equipped with motorized spindles. Unlike externally driven spindles, the motorized spindles do not require mechanical transmission elements like gears and couplings [2].

High-speed motorized spindle is an important component of the high-speed machine tools its performance decides the level of the whole machine tools development to some extent. So high-speed machine tools have strict requirements for technical indexes of the motorized spindle, which is different from traditional spindle system. The safety and reliability due to imperfect dynamic performance have become the primary problem of structural design and machine operation. Therefore, the dynamic performance research of the high-speed motorized spindle has an important theoretical and practical significance [3]. As the FEM (finite element method) has become an essential solution technique in many areas of engineering concerned static and dynamic process, the FEM is utilized in the design of motorized spindle bearing system [4]. The static and dynamic characteristics, the thermal characteristics, and the centrifugal-force induced characteristic variations of motorized spindle bearing system were analyzed by using FEM [5-7].

CX series vertical milling compound machining center is one of the national major technology subjects of "High-grade $\mathrm{NC}$ machine tools and basic manufacturing equipment". It is one of the national key research projects of China. Motorized spindle is used in CX8075 series vertical milling compound machining center. The maximum rotating speed of the motorized spindle is greater than or equal to $12,000 \mathrm{rpm}$. Motorized spindle is one of the key parts of CX8075. 


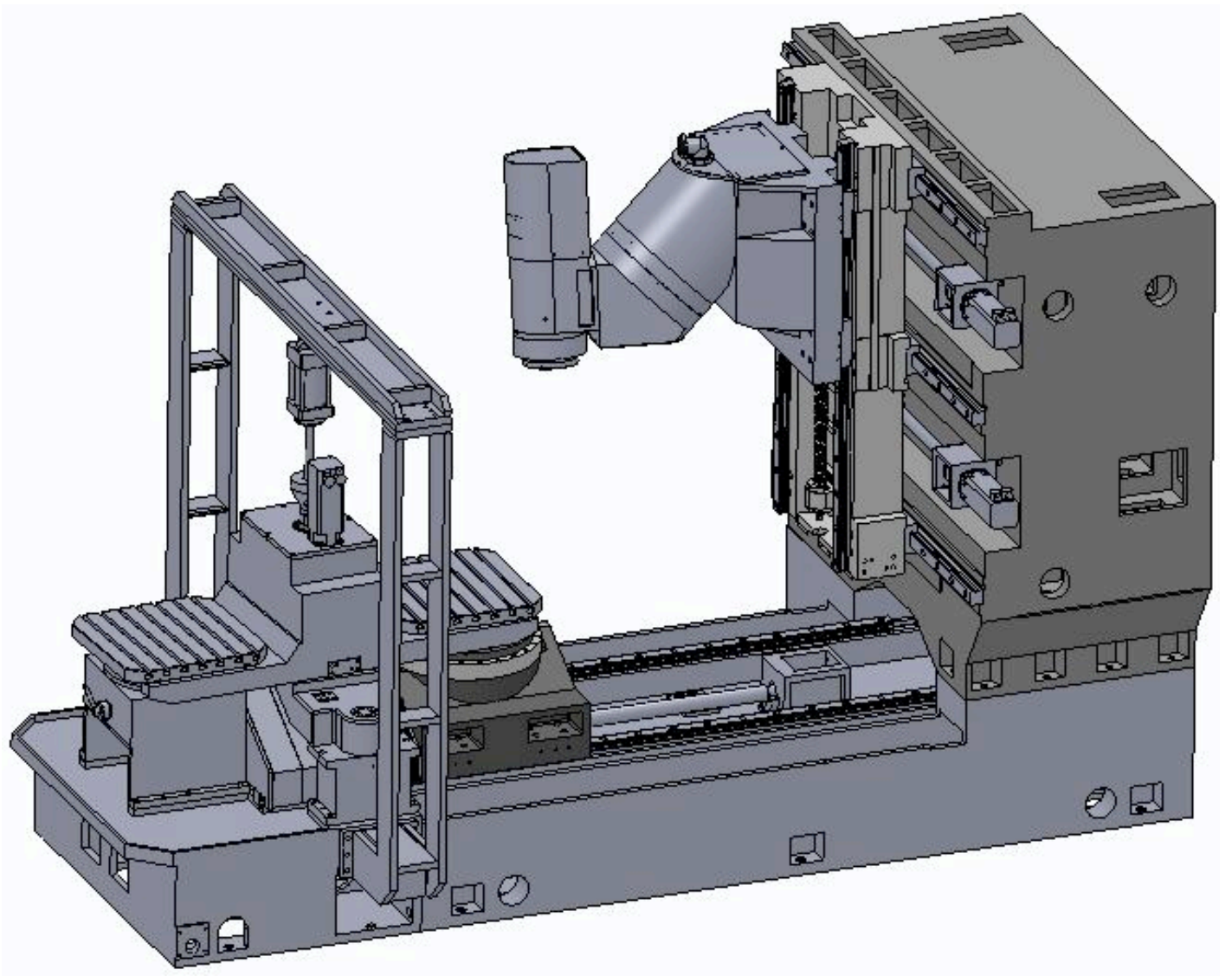

Fig. (1). Assembly drawing of CX8075.

The aim of this paper is to develop a finite element model of the high-speed motorized spindle. The model takes into account bearing support contact interface. The simulations of static, modal, harmonic response and thermal deformation are conducted by using ANSYS commercial software. The static, dynamic and thermal characteristics of the motorized spindle are analyzed and verified by the result of simulation.

\section{CX8075 AND MOTORIZED SPINDLE STRUCTURE}

Taking the swing milling head of the CX8075 vertical milling compound machining center produced by Anyang Xinsheng Machine Tool Co. Ltd. as an example, the maximum rotating speed of the motorized spindle is greater than or equal to $12,000 \mathrm{rpm}$, and the fast moving speed of feeding system $(\mathrm{X} / \mathrm{Y} / \mathrm{Z}$ axis) is greater than or equal to $60 \mathrm{~m} / \mathrm{min}$. The virtual assembly result of CX8075 is shown in Fig. (1).

The structure of the spindle is shown in Fig. (2). In order to meet the requirements of high-speed processing, the standardized tool interface HSK(Hohlschaftkegel) is placed at the spindles front end. The spindle is supported by two sets of angular contact ball bearings which are XCB series super precision spindle bearings produced by the FAG in Germany. For the sake of reducing the axial runout of the spindle and improving the axial stiffness of the spindle, the two sets of angular contact ball bearings are installed in the back to back.

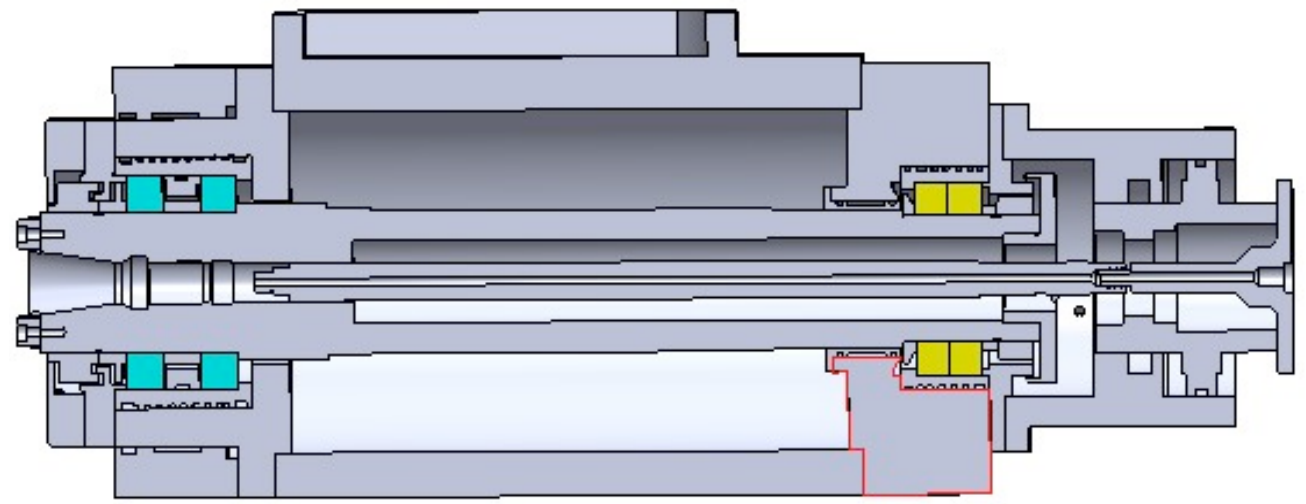

Fig. (2). Mechanical structure of a spindle. 


\section{FOUNDATION OF THE FINITE ELEMENT MODEL}

A motorized spindle assembly is composed of a large number of different parts and subassemblies, many of which are complex. However, research has shown that a model of a motorized spindle may be obtained experimentally [8]. In fact, the spindle can be modeled as a shaft, supported at each end by a set of bearings. This representation has been used in $[9,10]$. Fig. (3) shows a diagram of the simplified representation of the spindle system considered herein [11]. The

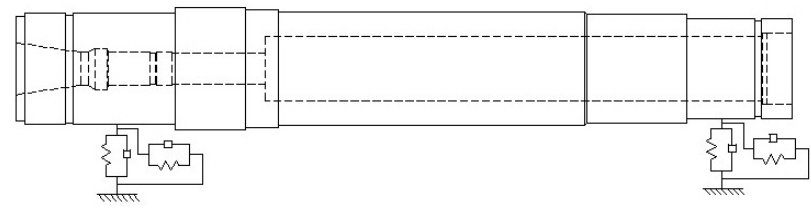

Fig. (3). Equivalent dynamic model of a spindle.

model of the high-speed milling motorized spindle is established by ANSYS commercial software. Spring-damper element is applied to simulate the elastic support of the two sets of bearings. Four spring damper units uniformed along the circumferential direction of the spindle, which is shown in Fig. (4).

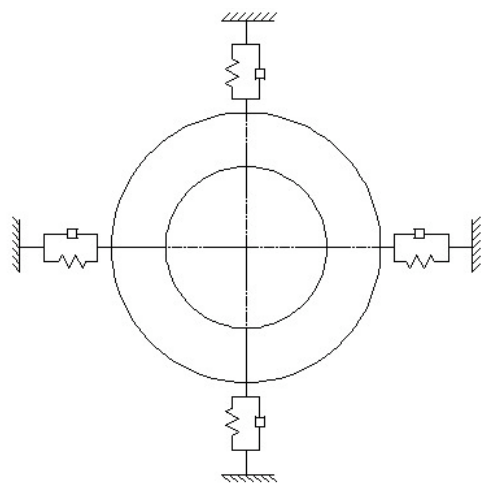

Fig. (4). Layout of spring damper unit.
COMBIN14 element which can be applied to simulate springs and dampers is provided in ANSYS commercial software. The Solid 92 element which is a tetrahedral element with ten nodes is used to simulate spindle part. The finite element model is shown in Fig. (5). The total numbers of nodes and elements are 55,689 and 35,231, respectively. The material of the spindle is $40 \mathrm{Cr}$. When assigned material number to the model in ANSYS, the quality of the spindle is $27.6263 \mathrm{~kg}$. The required mass of the spindle is $27.5 \mathrm{~kg}$. For the necessary simplification in the process of model establishment, the model of the spindle is reasonable.

The spring stiffness and damper parameter of the springdamper element COMBIN 14 are necessary for finite element analysis. In the condition of having known the axial preloading $\mathrm{Fa}_{0}$, the radial stiffness of the angular contact ball bearings can be calculated as follows [12]:

$$
K_{r}=1.77236 \times 10^{7} \times k_{m}\left(z^{2} \cdot D_{w}\right)^{1 / 3} \frac{\cos ^{2} \alpha}{\sin ^{1 / 3} \alpha}\left(F_{a 0}\right)^{1 / 3}(N / m)
$$

The bearing types are XCB7017C.T.P4S and XCB7018C.T.P4S [13]. The spring stiffness of each set of bearings is $310.3 \mathrm{~N} / \mu \mathrm{m}$ and $274.3 \mathrm{~N} / \mu \mathrm{m}$ according to Eq. 1 . Because the damper has little influence on the natural frequency of the transversal vibration, the damper element can be ignored.

\section{STATIC ANALYSIS OF THE SPINDLE}

In the engineering, there are few cases of machine failure owing to the fatigue fracture of the spindle, but there are many cases of machine failure as a result of spindle's large deformation self-excited vibration under the action of the cutting force. Therefore, the static design of the milling spindle unit is mainly related with the static stiffness of the spindle which is referred to spindle stiffness. The spindle stiffness is closely related with the load capacity and vibration resistance, which is an important performance index of the motorized spindle.

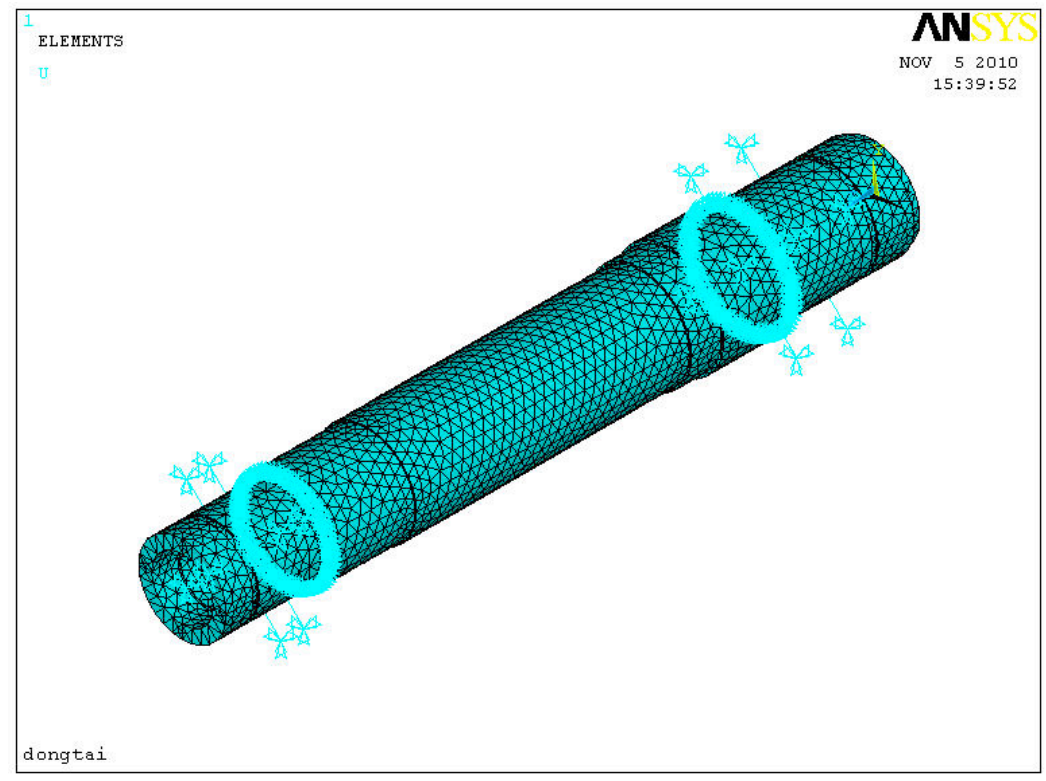

Fig. (5). Model of FEM mesh. 
The spindle stiffness includes the axial and bending stiffness. In normal operating condition, the bending stiffness is more important than axial stiffness. The bending stiffness $(K)$ of the spindle unit is defined as follows: if the front part of the spindle generates unit radial displacement $\delta$, the force required to be imposed on the direction of the displacement is $\operatorname{Fr}[12]$ :

$K=F r / \delta(\mathrm{N} / \mu \mathrm{m})$

In the study of the static load analysis of spindle, the rotating speed loading analysis is done at first, and the maximum rotating speed of the motorized spindle is greater than or equal to $12000 \mathrm{rpm}$. The analysis result of rotating speed loaded is shown in Fig. (6). The maximum deformation is only 3.67 micron, which basically does not affect the precision of the spindle.

Then the loading cutting force analysis is done. The PIPE16 element is applied to simplify the spindle, and COMBIN14 element to simplify spindle bearing support. The result is shown in Fig. (7). The maximum deformation is 11.1 micron when loading the main cutting force $2305 \mathrm{~N}$. Thus, the static stiffness of spindle can be calculated, whose result is $207.66 \mathrm{~N} / \mu \mathrm{m}$ according to Eq. 2 .

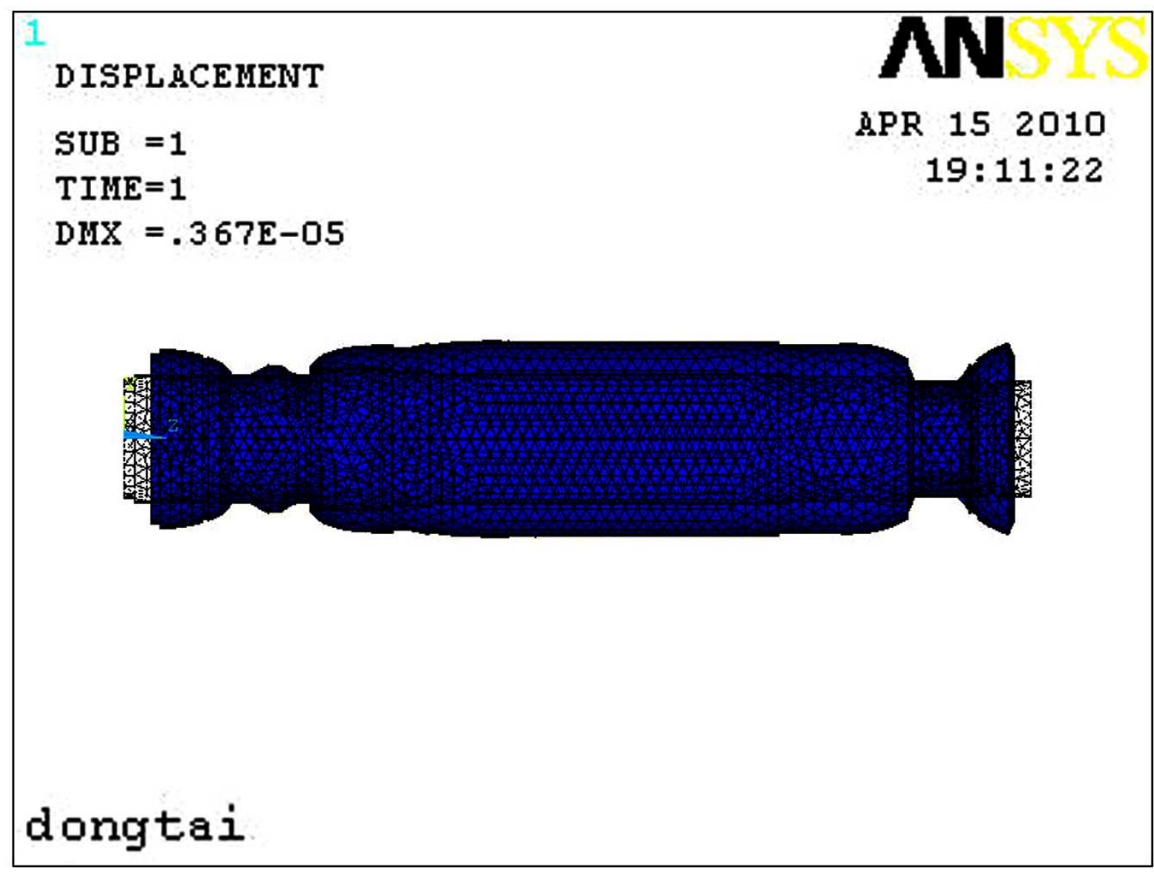

Fig. (6). Deformation of rotating speed loading.

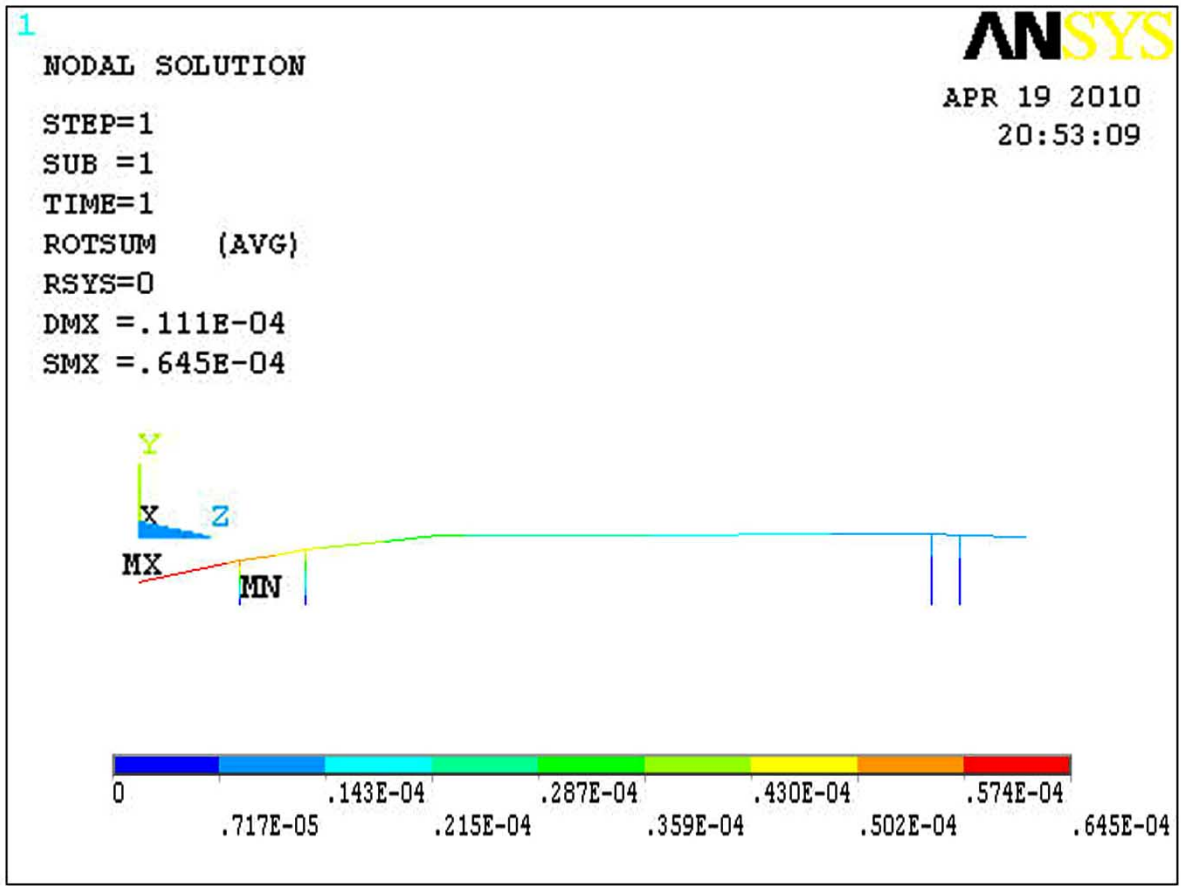

Fig. (7). Deformation of cutting force loading. 


\section{MODAL ANALYSIS OF THE SPINDLE}

Milling motorized spindle vibration is inevitable during milling, which not only changes the relative position of work pieces and milling cutters to influence the machining accuracy, but also accelerates the wears of milling cutter, further influencing the machining accuracy. Research shows that the processing quality largely depends on the vibration produced by machine. Especially for high speed machine tools with high accuracy, the influence of vibration is even more serious. Therefore, the modal of spindle is the primary problem of dynamic characteristics analysis.

\subsection{The Spindle Modal without Bearing Support}

The spindle each order natural frequencies and corresponding rotating speed are shown in Table 1. Because all freedoms of the spindle are not restricted actually, the former 6 order natural frequencies of the spindle are zero.

Table 1. Frequency and Rotating Speed in each Order without Bearing Support

\begin{tabular}{|c|c|c|c|c|c|}
\hline Order & $\mathbf{6}$ & $\mathbf{7}$ & $\mathbf{8}$ & $\mathbf{9}$ & $\mathbf{1 0}$ \\
\hline \hline Freq(HZ) & 0 & 1091.3 & 1091.3 & 2518.9 & 2579.8 \\
\hline Rev(r/min) & 0 & 65478 & 65478 & 151134 & 154788 \\
\hline
\end{tabular}

The natural frequency of the 7th and the 8th of the spindle are equal, the vibration model is shown in Fig. (8) and Fig. (9). They are mutually orthogonal, as first-order bending vibration. The corresponding rotating speed is $65,478 \mathrm{rpm}$,

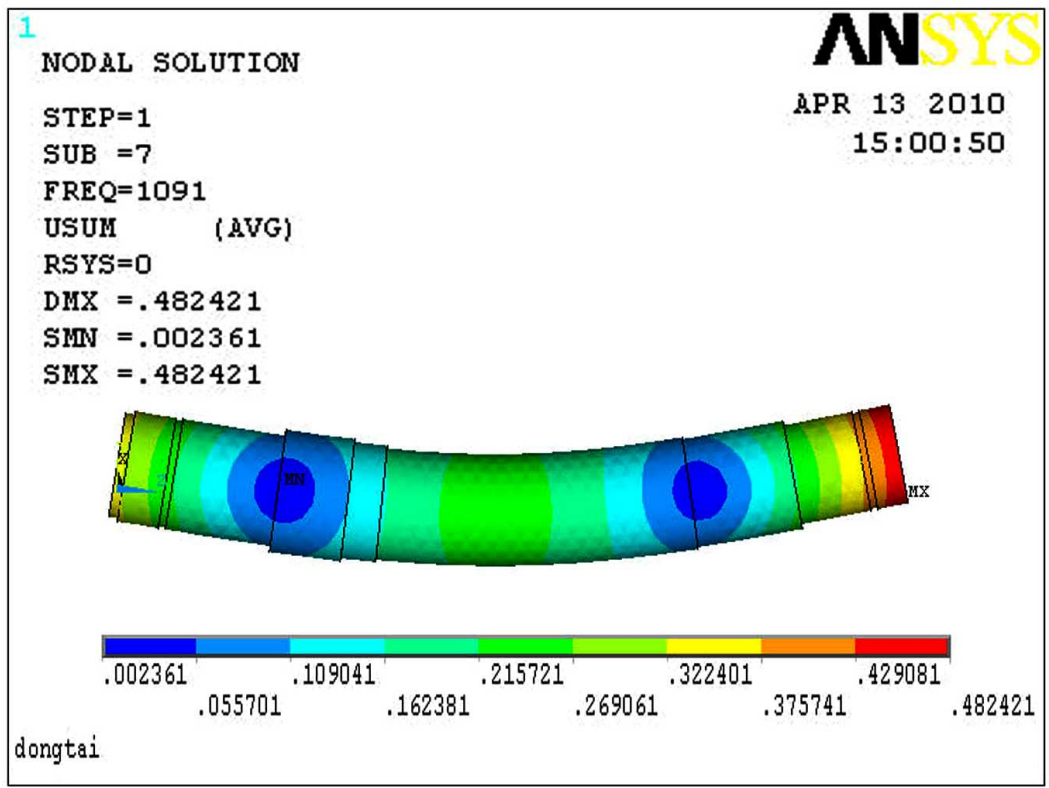

Fig. (8). The $7^{\text {th }}$ vibration mode of a spindle without bearing support.

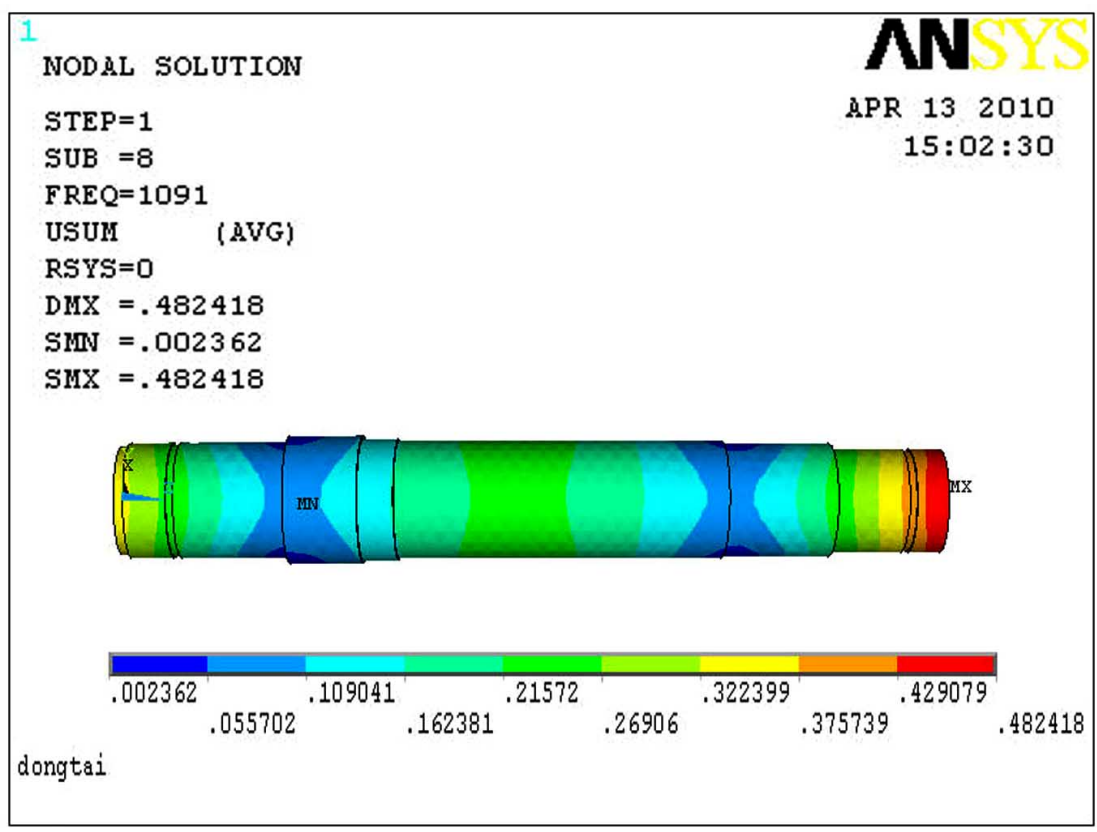

Fig. (9). The $8^{\text {th }}$ vibration mode of a spindle without bearing support. 
which is much greater than the working rotating speed $12,000 \mathrm{rpm}$.

\subsection{The Spindle Modal with Bearing Support}

With the bearing bounded state, the spindle former 5 natural frequencies and corresponding rotating speed are shown in Table 2. The first-order frequency is zero which is the result of the axial rotating freedom of the spindle is not restricted actually.

Table 2. Frequency and Rotating Speed in each Order with Bearing Support

\begin{tabular}{|c|c|c|c|c|c|}
\hline Order & $\mathbf{1}$ & $\mathbf{2}$ & $\mathbf{3}$ & $\mathbf{4}$ & $\mathbf{5}$ \\
\hline \hline Freq(HZ) & 0 & 1054.6 & 1056.0 & 1602.3 & 1602.6 \\
\hline Rev(r/min) & 0 & 63276 & 63360 & 96138 & 96156 \\
\hline
\end{tabular}

As the spindle is restricted by the spring-damper element, the 2 nd and the 3rd natural frequency of the spindle is similar, the vibration mode is shown in Fig. (10) and Fig. (11). They are mutually orthogonal too. The corresponding rotating speed is $63,276 \mathrm{rpm}$, which is far away from the working rotating speed 12,000rpm. Through the above analysis, it is very obvious that the design of the spindle avoids the resonance region effectively, and the design of the milling motorized spindle is reasonable.

\section{HARMONIC RESPONSE ANALYSIS OF THE SPINDLE}

Harmonic response analysis is done on the basis of the modal analysis of the spindle in the way of the modal superposition. The computing time is effectively reduced on the basis of the completed modal analysis. For harmonic response, $100 \mathrm{~N}$ force is applied on the end of the spindle

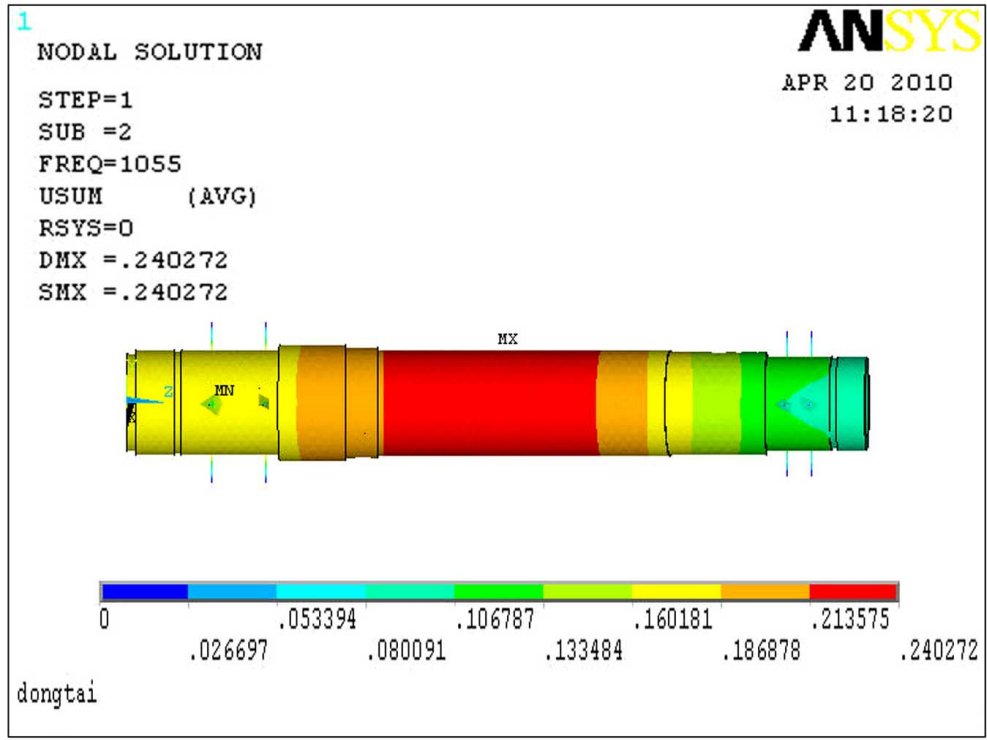

Fig. (10). The 2nd vibration mode of a spindle with bearing support.

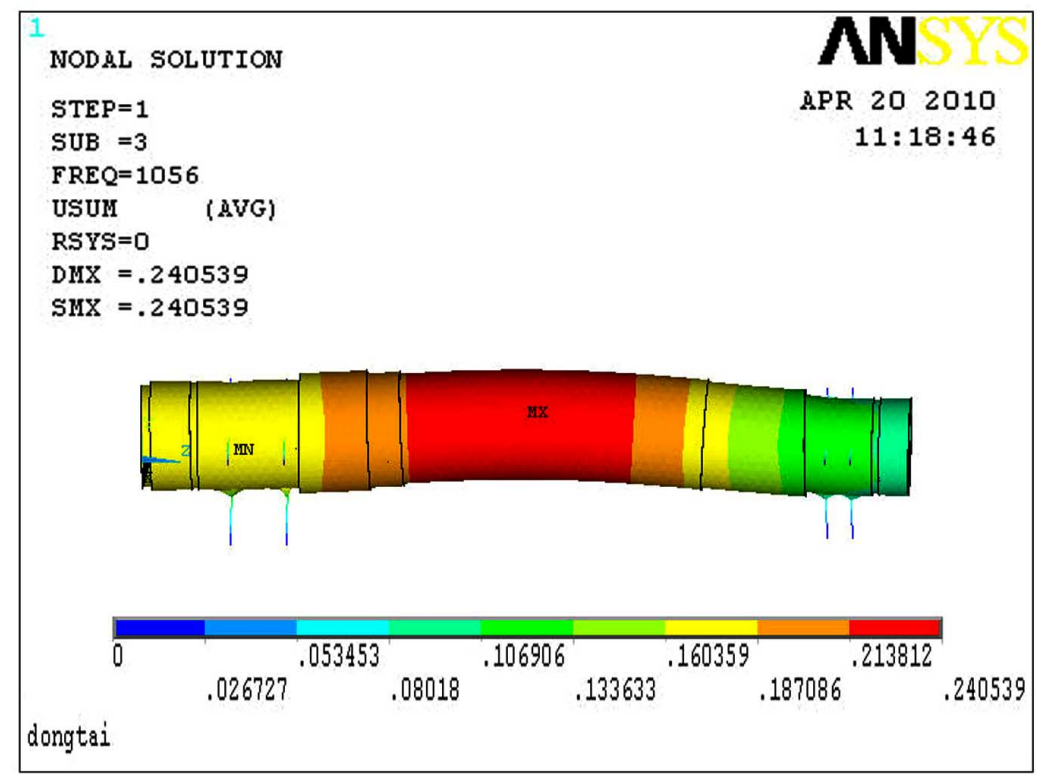

Fig. (11). The 3rd vibration mode of a spindle with bearing support. 


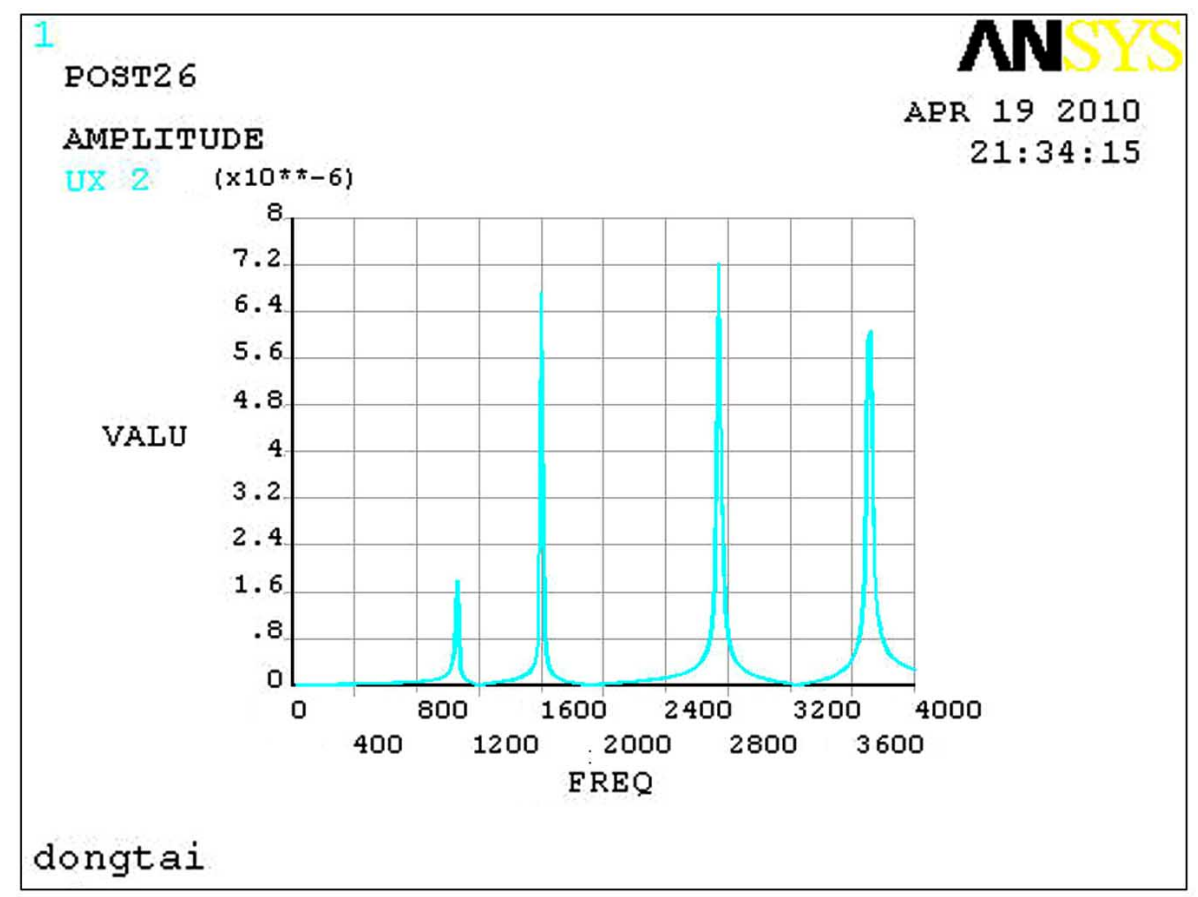

Fig. (12). Node harmonic response curve.

taper to analyze the 10 order frequency, whose range is from $0 \mathrm{~Hz}$ to $4,000 \mathrm{~Hz}$ with step $400 \mathrm{~Hz}$. Selecting a node from the cone part of spindle to analyze, the analysis result is shown in Fig. (12). From the graph, it can be seen that the node has vibration peak at $1,056 \mathrm{~Hz}, 1,602 \mathrm{~Hz}, 2,746 \mathrm{~Hz}$ and $3,710 \mathrm{~Hz}$. The maximum vibration peak appears at $2,746 \mathrm{~Hz}$ which is $7.22 \mu \mathrm{m}$. The vibration is only $0.009,93 \mu \mathrm{m}$ at the working frequency of $200 \mathrm{~Hz}$, which has virtually no influence on spindle.

\section{THERMAL ANALYSIS OF THE SPINDLE}

Limits of a spindle's speed, reliability and performance are usually constrained by properties of its bearings, which are affected by the uneven thermal expansion of spindle parts and degraded condition of lubricants due to high temperature. The most significant parameter affecting the spindle thermal displacement is the friction heat in the front and back bearings of the spindle. When the spindle rotates, heat occurs at the front and back bearings because of friction, and the heat is then transmitted to the spindle head and tool header etc. Thermal displacement consequently occurred at the spindle because of temperature increase.

\subsection{The Finite Element Model of Thermal Analysis}

In order to analysis the thermal deformation of motorized spindle, the analysis of thermal-structural coupled field is

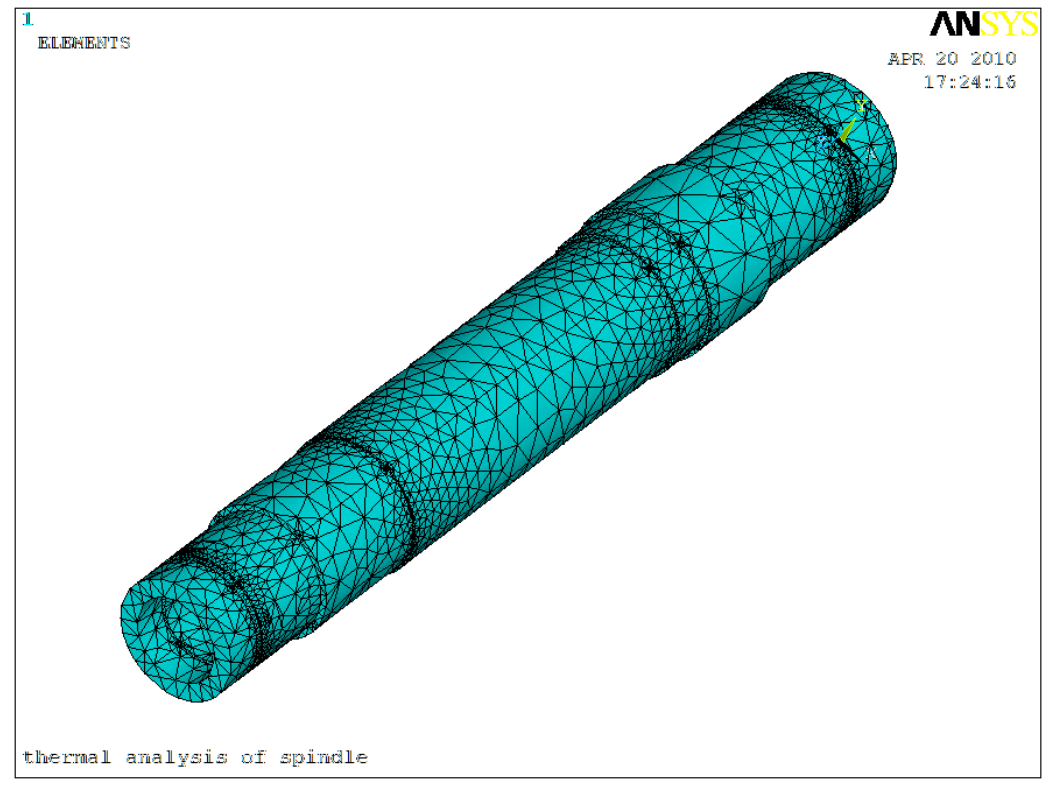

Fig. (13). The thermal deformation model of spindle. 
needed. Analysis of thermal-structural coupled field can be carried out by direct coupling method and indirect coupling method. The element of direct coupling method requires thermal and structure of degrees of freedom, direct coupling method can draw coupling field analysis results only through one solution, such as temperature distribution and structure deformation. Indirect coupling method takes the results of the first analysis as the load of the second analysis to realize two field coupling. Direct coupling method is used to analyze the motorized spindle in this paper. The Solid 227 element which is a thermal-structural coupled element, is used to mesh the spindle part. In order to be used in direct thermal-structural coupling analysis, the freedom of $U x, U y$, $\mathrm{Uz}$ and Temp need to be selected when definition the attributes of solid 227 element. The bearings on both ends of spindle need to be simplified in the finite element model, structure freedom and the thermal load are set at bearing installation site. The finite element model of spindle thermal deformation is showed in Fig. (13).

\subsection{The Boundary Conditions of Thermal Deformation}

Considering the high-speed axial load factor, and the spindle bearing pressure angle for $15^{\circ}$, the thermal value of bearing is according to Eq. 3 .

$Q=1.047 \times 10^{-4} n M$

In Eq. 3, $n$ is the rotating speed of bearing, $M$ is the friction torque of bearing. The friction torque $M=M_{0}+M_{l}$, and $M_{0}$ is relevant with the rotating speed of bearing. When bearing in low speed and heavy load conditions, $M_{1}$ is occupied the main part of $M$, when bearing in high-speed and light load conditions, $M_{0}$ is occupied the main part of $M$.

In the motorized spindle thermal analysis, the thermal value of bearing load applied to bearing installation position. The thermal production rate of bearing is $6 \times 10^{6} \mathrm{~W} / \mathrm{m}^{3}$ according to calculation.
Convection, conduction and radiation are three kinds of method of heat transmittance. Because the temperature rise of machining center spindle system is smaller than the other method, the lost thermal of radiation is rarely. Therefore the former two kinds of methods are considered into this analysis.

The working environment temperature of motorized spindle is set to $25^{\circ}$, the rotating speed is $12000 \mathrm{rpm}$, the convection heat transfer coefficient between spindle and ambient air is $250 \sim 260 \mathrm{~W} /\left(\mathrm{m}^{2} \cdot{ }^{\circ} \mathrm{C}\right)$. The material of the spindle is $40 \mathrm{Cr}$, its thermal conductivity is $91.3 \mathrm{~W} /(\mathrm{m} \cdot \mathrm{K})$.

Considering the support type of spindle bearing, the freedom of Ux, Uy and Uz at one bearing are fixed, and the freedom of $U x$ and $U y$ at another bearing are fixed. The boundary conditions of thermal deformation loading are shown in Fig. (14).

\subsection{The Thermal Deformation of Motorized Spindle}

The thermal steady-state analysis is done by means of ANSYS, the temperature distribution of motorized spindle is shown in Fig. (15). Because calorific value of bearing is larger than other place, the bearing in front and back of motorized spindle is in high temperature. The highest temperature occurs in the inner ring of the former bearing. Research shows that thermal deformation is the main factors which causing deformation of the spindle.

After spindle reached thermal equilibrium, the thermal deformation analysis of spindle is done according to the results of temperature distribution. The thermal deformation of spindle is shown in Fig. (16). The largest thermal deformation of spindle is $6.56 \mu \mathrm{m}$, appears in the front-end of the spindle. It basically does not affect the precision of the spindle.

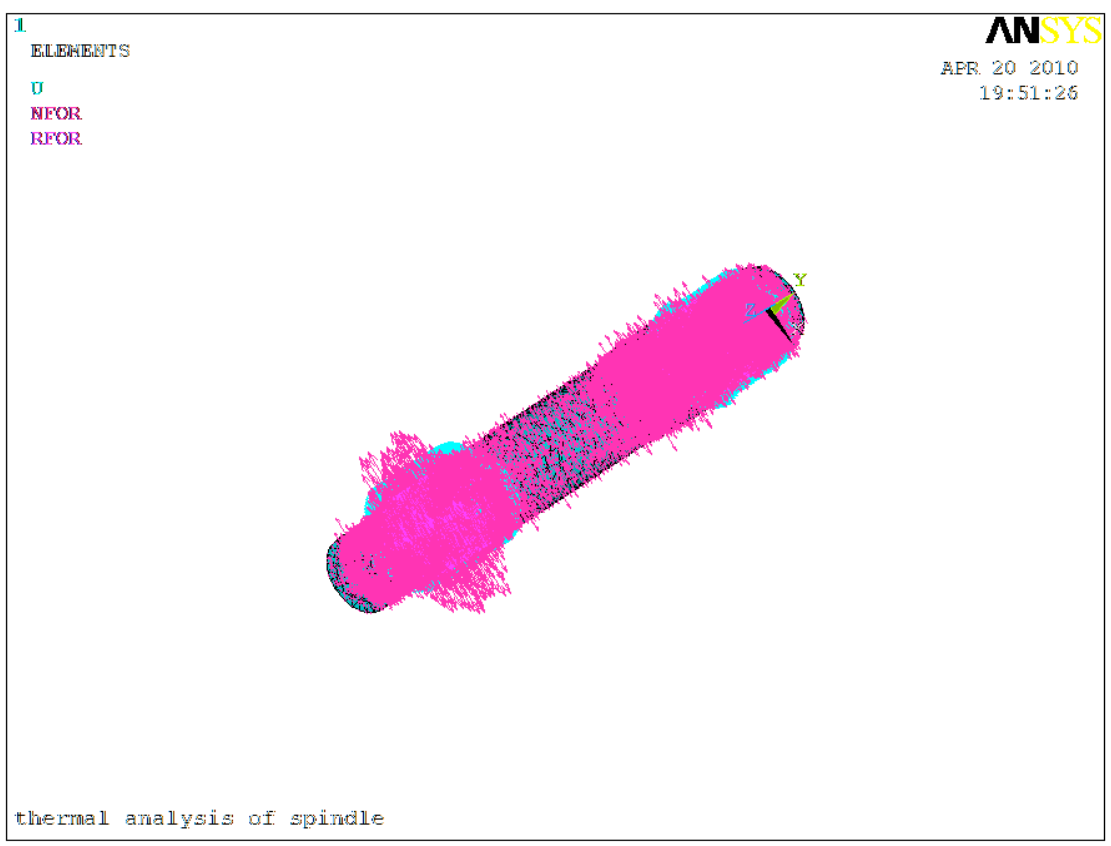

Fig. (14). The boundary conditions loading. 


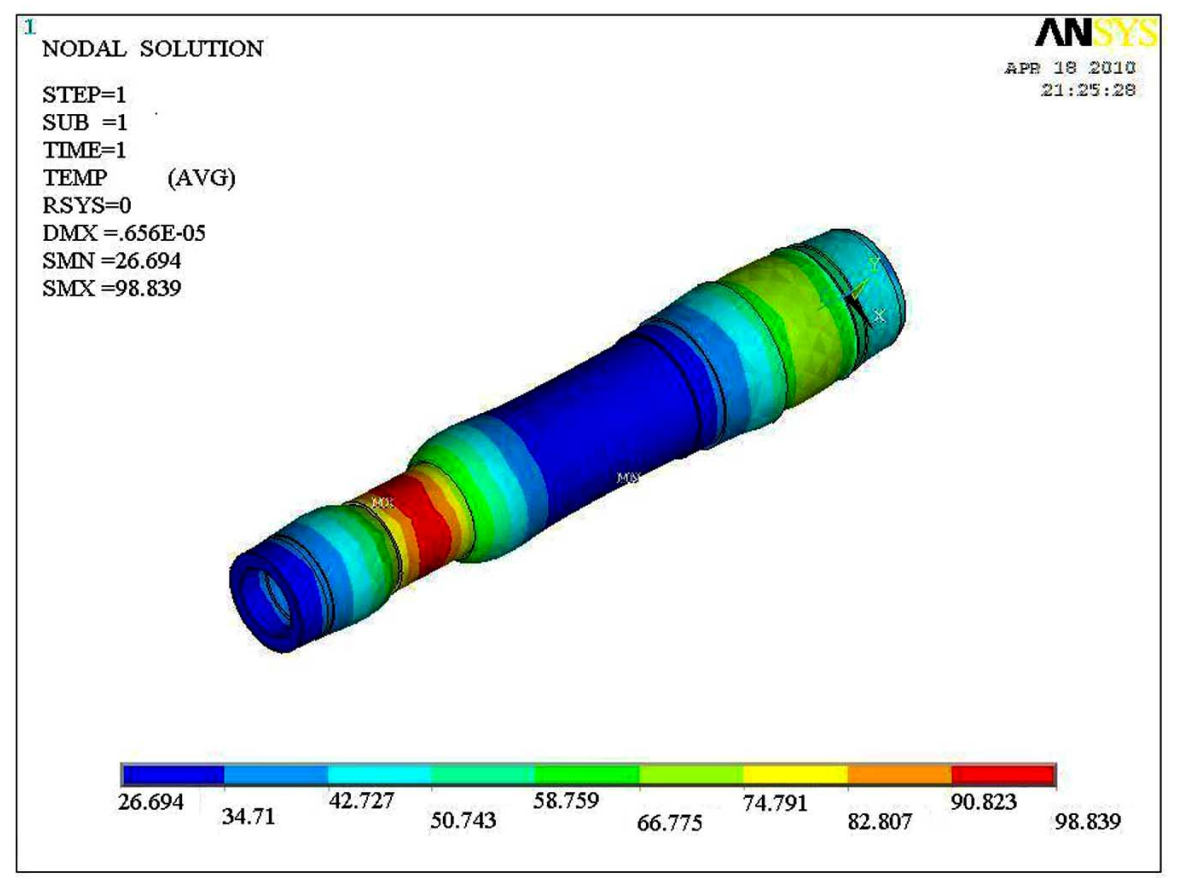

Fig. (15). The temperature distribution of spindle.

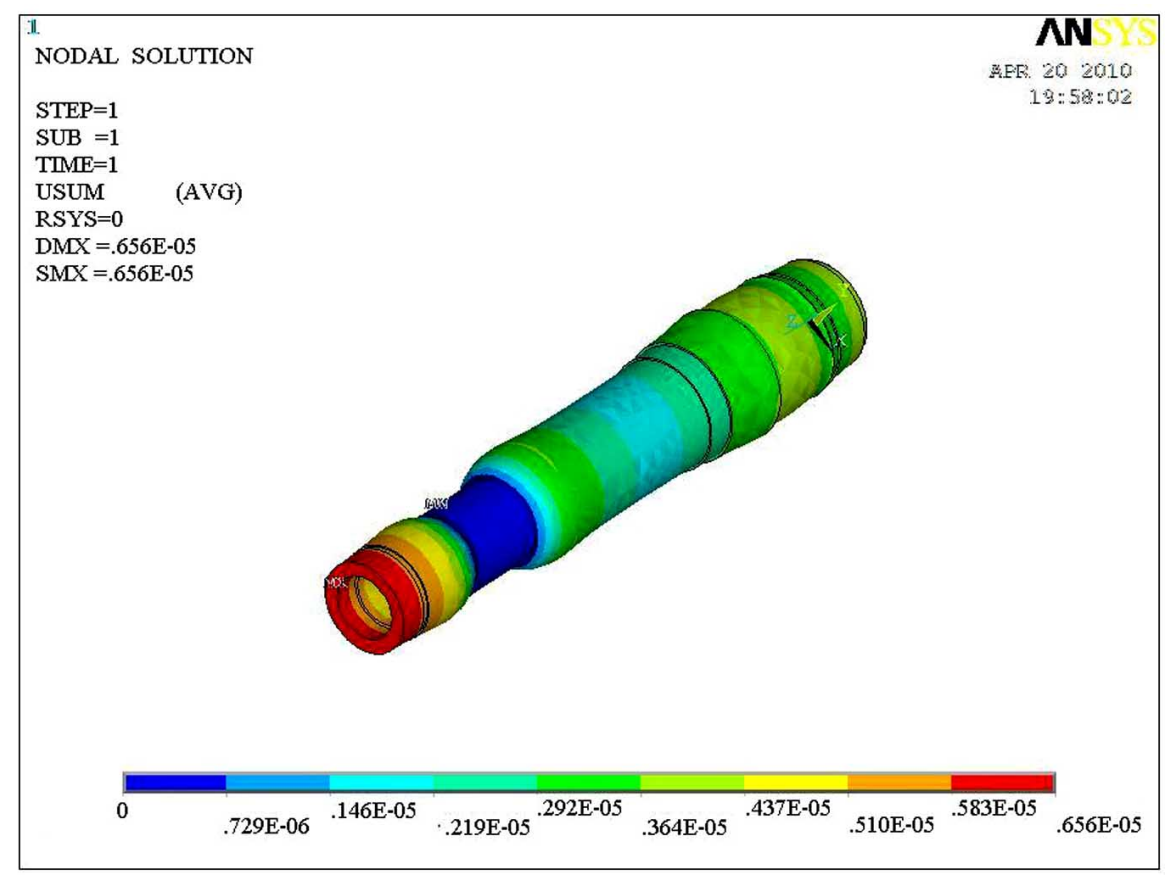

Fig. (16). The thermal deformation of spindle.

\section{CONCLUSIONS}

(1) The method of finite element modeling about milling motorized spindle of CX8075 vertical milling compound machining center was studied. A finite element model of the high-speed motorized spindle is derived and presented. The model takes into account bearing support contact interface, which is established by spring-damper element COMBIN 14.

(2) The static analysis, the model analysis harmonic response and thermal analysis were done by means of ANSYS. The method to establish the finite element model of the bearing support by spring-damper element COMBIN 14 was investigated and tested.

(3) The results of static analysis show that the stiffness of spindle is $207.66 \mathrm{~N} / \mu \mathrm{m}$, which is strong for a motorized spindle. The results of modal analysis show that the first-order natural frequency of the spindle is $1054.6 \mathrm{~Hz}$, the first-order critical rotating speed is $63,276 \mathrm{rpm}$ which is away from the maximum rotating speed of the motorized spindle, 12,000 rpm. The results of thermal analysis show that the thermal deformation of spindle is $6.56 \mu \mathrm{m}$, which is too small to affect the precision of the spindle. 
(4) The requirements of high-speed processing are meet by analyzing static and dynamic characteristics of the motorized spindle. The rationality of the spindle structural design is verified by FEM analysis. The result shows that the method to establish the finite element model of the bearing support by spring-damper element can be applied to the spindle component analysis and optimization.

\section{ACKNOWLEDGEMENTS}

The authors gratefully acknowledge the financial support provided by the Ministry of Industry and Information Technology of PRC through project (2009ZX04001-033). Prof. Yuping Wang of Anyang Xinsheng Machine Tool Co. Ltd. and Prof. Wufa Liu of Zhengzhou University are gratefully acknowledged for their support during this work.

\section{REFERENCES}

[1] Z.-C. Lin, and J.-S. Chang, "The building of spindle thermal displacement model of high speed machine center", Int. J. Adv. Manuf. Technol., vol. 34, pp. 556-566, Sept. 2007.

[2] E. Abele, Y. Altintas, and C. Brecher, "Machine tool spindle units", CIRP Annals - Manuf. Technol., vol. 59, pp. 781-802, 2010.

[3] C. Li, Y. Ding, and B. Lu, "Development and Key Technology in High Speed Cutting", J. Qingdao Technol. Univ., vol. 30, pp. 7-16, Feb. 2009.
[4] W. Li, H. Pu, Q. Liu, G. Chen, and S. Zhang, "ANSYS-Based dynamic analysis of high-speed motorized spindle", Int. Conf. Comput. Eng. Technol., 2009, pp. 336-340.

[5] J. K. Choi, and D. G. Lee, "Characteristics of a spindle bearing system with a gear located on the bearing span". Int. J. Mech. Tool. Manuf. Pergamon, vol. 37, pp. 171-173, Aug. 1997.

[6] J. K. Choi, and D. G. Lee, "Thermal characteristics of the spindle bearing system with a gear located on the bearing span", Int. J. Mech. Tool. Manufact. Pergamon, vol. 38, pp. 1017-1030, Sept. 1998

[7] J.-S. Chen, and Y.-W. Hwang, "Centrifugal force induced dynamics of a motorized high-speed spindle", Int. J. Adv. Manuf. Technol., vol. 30, pp. 10-19, Aug. 2006.

[8] A. G. Rehorn, "Spindle Dynamics: Identification, Modeling and Effects", M. S. thesis, University of Western Ontario, Ontario, Canada, 2001.

[9] E. V. Bordatchev, and R. Henriksen, "State space modeling of machine tool spindle units using subspace identification", Proceedings of the 2nd IASTED International Conference on Control and Application, 1999, pp. 120-123.

[10] E. V. Bordatchev, "Modeling and parameter identification of the impulse response matrix of mechanical systems", Proceedings of SPIE - The International Society for Optical Engineering, 1998, pp. 106-117.

[11] A. G. Rehorn, J. Jiang, P. E. Orban, and E. Bordatchev, "Modelling and experimental investigation of spindle and cutter dynamics for a high-precision machining center", Int. J. Adv. Manuf. Technol., vol. 24, pp. 806-815, Dec. 2004.

[12] W. Xie, "The FEM Analysis of Dynamic and Static Characteristic of High Speed Motorized Spindle", M. S. thesis, Harbin Institute of Technology, Harbin, PRC, 2001

[13] R. A. Burton, and H. E. Staph, "Thermally Activated Seizure of Angular Contact Bearings”. A.S.L.E. - Transactions, vol. 10, pp. 408-417, Oct. 1967. 